
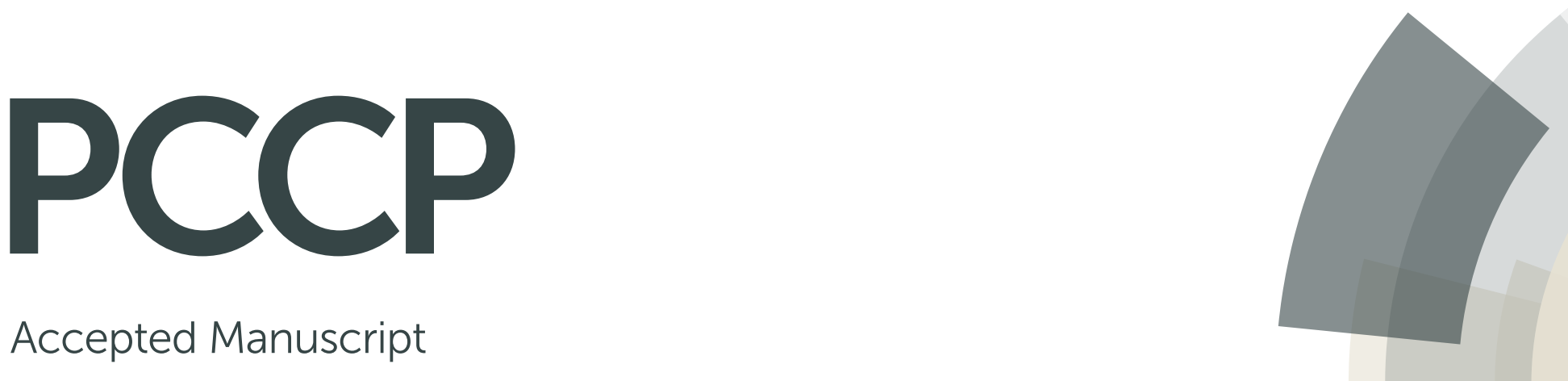

Accepted Manuscript

This article can be cited before page numbers have been issued, to do this please use: A. N. N. Petelski, S. C. Pamies, A. G. Sejas, N. M. Peruchena and G. L. Sosa, Phys. Chem. Chem. Phys., 2019, DOI:

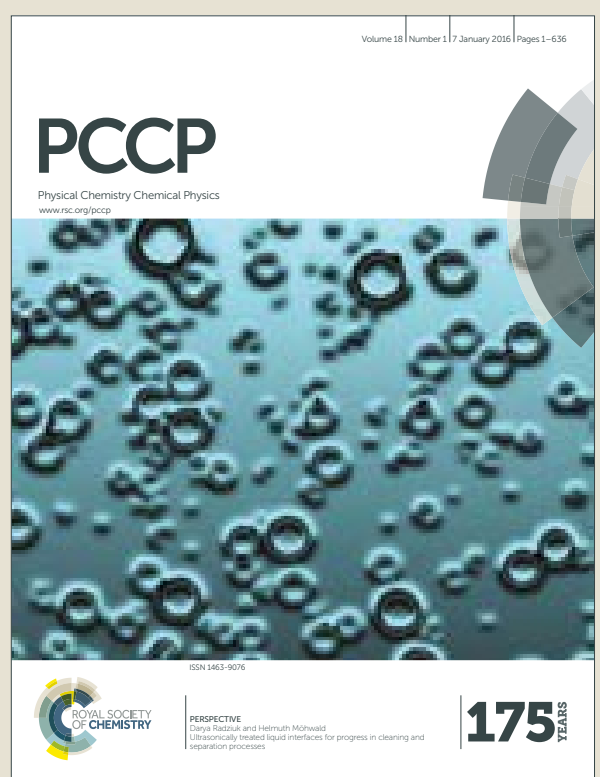

This is an Accepted Manuscript, which has been through the Royal Society of Chemistry peer review process and has been accepted for publication.

Accepted Manuscripts are published online shortly after acceptance, before technical editing, formatting and proof reading. Using this free service, authors can make their results available to the community, in citable form, before we publish the edited article. We will replace this Accepted Manuscript with the edited and formatted Advance Article as soon as it is available.

You can find more information about Accepted Manuscripts in the author guidelines.

Please note that technical editing may introduce minor changes to the text and/or graphics, which may alter content. The journal's standard Terms \& Conditions and the ethical guidelines, outlined in our author and reviewer resource centre, still apply. In no event shall the Royal Society of Chemistry be held responsible for any errors or omissions in this Accepted Manuscript or any consequences arising from the use of any information it contains. 


\section{Impact of Confinement in Multimolecular Inclusion Compounds of Melamine and Cyanuric Acid}

Received 00th January 20xx, Accepted 00th January 20xx

DOI: $10.1039 / \times 0 x \times 00000 x$

www.rsc.org/

\author{
Andre Nicolai Petelski, ${ }^{\text {a,c }}$ Silvana Carina Pamies, ${ }^{a}$ Agustín Gabriel Sejas, ${ }^{a}$ Nélida María Peruchena, ${ }^{* b, c}$ \\ and Gladis Laura Sosa*a,c
}

\begin{abstract}
Supramolecular cavities can be found in clathrates and self-assembling capsules. In these computational experiments, we studied the effect of folding planar hydrogen-bonded supramolecules of melamine $(\mathrm{M})$ and cyanuric acid (CA) into stable cage-like quartets. Based on dispersion-corrected density functional theory calculations at the $\omega B 97 X D / 6-311++G(d, p)$ level, we show the flexibility of $\mathrm{M}$ and CA molecules to form free confined spaces. Our bonding analysis indicates that only CA can form a cage which is more stable than their planar systems. We then studied the capacity of the complexes to host ionic and neutral monoatomic species like $\mathrm{Na}^{+}, \mathrm{Cl}^{-}$and $\mathrm{Ar}$. The encapsulation energies range from -2 to $-65 \mathrm{kcal}^{\mathrm{mol}}{ }^{-1}$. A detailed energy decomposition analysis (EDA) support the fact that the triazine ring of CA is superior to the $\mathrm{M}$ one to capture chloride ions. In addition, the EDA and the topology of the electron density, by means of the Atoms in Molecules (AIM) theory and electrostatic potential maps, reveal the nature of the host-guest interactions in the confined space. The CA cluster appears to be the best multimolecular inclusion compound because it can host the three species and keep its cage structure, and therefore could also act as a dual receptor of the ionic pair $\mathrm{Na}^{+} \mathrm{Cl}^{-}$. We think these findings could inspire the design of new heteromolecular inclusion compounds based on triazines and hydrogen bonds.
\end{abstract}

\section{Introduction}

Extramolecular, exomolecular, or multimolecular inclusion compounds are special cases within host-guest chemistry, in which more than one molecule creates the cavity for the guest complexation. ${ }^{1}$ In this context, non-covalent interactions play a fundamental role. Firstly, they are responsible of keeping the cavity, and second, they hold the guest inside it. These systems have aroused a great volume of research ${ }^{2,3}$ due to their promising applications; for instance, sequestration of small molecules, gases and ionic species.

Clathrates are the most well-known multimolecular inclusion compounds found in the crystal state, being hydroquinone clathrates the most representative ones. It has been shown that hydroquinone can form these structures with several molecules and atomic species, like $\mathrm{Xe},{ }^{4}$ hydrochloric acid, ${ }^{5}$ carbon dioxide, ${ }^{6}$ methanol and acetonitrile. ${ }^{7}$ When clathrates are formed, a special arrangement of the multimolecular host is only stabilized due to the presence of the guest. This process is the result of a balance between attractive

\footnotetext{
a. Grupo de Investigación en Química Teórica y Experimental (QuiTEx), Departamento de Ingeniería Química, Facultad Regional Resistencia, Universidad Tecnológica Nacional, French 414 (H3500CHJ), Resistencia, Chaco, Argentina. Email: glsosa@frre.utn.edu.ar.

b. Laboratorio de Estructura Molecular y Propiedades, Facultad de Ciencias Exactas y Naturales y Agrimensura, Universidad Nacional del Nordeste, Avenida Libertad 5460, 3400 Corrientes, Argentina.E-mail: arabeshai@yahoo.com.ar.

c. Instituto de Química Básica y Aplicada del Nordeste Argentino, IQUIBA-NEA, UNNE-CONICET, Avenida Libertad 5460, 3400 Corrientes, Argentina.

Electronic Supplementary Information (ESI) available: [details of any supplementary information available should be included here]. See DOI: 10.1039/x0xx00000x
}

and repulsive forces. Takasuke Matsuo has indicated there is cooperative molecular recognition in the formation course, ${ }^{1}$ and other authors have assumed there is no specific bond between the host and the guest molecules. ${ }^{6}$ Nevertheless, $M$. Ilczyszyn et al. ${ }^{8}$ have reported hydrogen bonds between the Xe atoms and the $-\mathrm{OH}$ groups that form the cavity within the famous Hydroquinone@Xe clathrates, which is a very specific interaction. Although they are classified as Van der Waals molecules because they are weakly bound, these type of systems are also hydrogen-bonded complexes. ${ }^{9}$

While metal-organic cages are widely known ${ }^{2}$ and have found many applications, ${ }^{10-12}$ hydrogen-bonded capsules are still in an early-stage advance. Rebek and coworkers have obtained, perhaps, the most prominent multimolecular hostguest complex: the tennis ball. ${ }^{13,14}$ Among others, they have created several self-assembling capsules, with the ability of capturing small molecules like methane, ${ }^{15}$ and even dimers. ${ }^{16,17}$ Atwood $^{18,19}$ and Whitesides ${ }^{20}$ have also mastered the supramolecular forces to create hydrogen-bonded capsules with enclosed spaces. In this context, triazine rings, like melamine (M) and cyanuric acid (CA), have shown to be suitable building blocks for creating supramolecular boxes in solution. ${ }^{21}$ In the solid state, for instance, Mascal et al. ${ }^{22}$ have obtained a cylindrophane based on two-faced CA rings that effectively captures fluoride ions. While Frontera et al. ${ }^{23}$ have crystalized complexes of CA molecules, which were previously covalently modified, with chloride ions.

The confinement of non-covalent interactions are also present in several host-guest systems, in which the host is a simple molecule. By far, calixarenes and cucurbituriles are the 
smallest molecules that can host atomic species and small molecules. Sashuk et al. ${ }^{24}$ have obtained a square shaped molecule that can capture a single water molecule or a fluoride anion. Endohedral fullerenes are also a matter of study in this field. Very recently, it has been shown that the confinement of anions within $\mathrm{C}_{60}$ turns them into big anions. ${ }^{25}$ Furthermore, the presence of cations was shown to drive the self-assembly of cavitands into multimolecular complexes. ${ }^{26}$

Chemical species have shown different properties when they are confined. For instance in catalysis, ${ }^{27}$ and hydrogenbonded systems. ${ }^{28,29}$ Therefore, in this work we investigate the impact of folding planar supramolecules of $M$ and CA into cageshaped complexes. We focus on the stability of hydrogen bonds and the free confined spaces they hold. We then analyze the capacity of the triazine rings and the chemical spaces to capture monoatomic species like $\mathrm{Na}^{+}, \mathrm{Cl}^{-}$and Ar. Finally, through our computational experiments, we demonstrate herein that $\mathrm{CA}$ is a more robust building block for fabricating supramolecular inclusion compounds.

\section{Computational Methods}

All computations were performed with dispersion corrected density functional theory (DFT-D) implemented in the Gaussian 03 package, ${ }^{30}$ by using the $\omega$ B97XD hybrid functional from Head Gordon et al. ${ }^{31}$ with the $6-311++\mathrm{G}(d, p)$ basis set. This method has proved to show a great performance in similar systems. ${ }^{32-34}$ The minimum energy nature of the optimized structures was verified using the vibrational frequency analysis.

The bonding energies $\Delta E_{\text {bond }}$ (Equation 1 ) were obtained at the same level of theory using the approach of Fonseca Guerra et $a l .{ }^{35}$, which is calculated as the sum between the interaction energy of the complex $\Delta E_{\text {int }}$ and the deformation energy $\Delta E_{\text {def. }}$.

$\Delta E_{\mathrm{bond}}=\Delta E_{\mathrm{int}}+\Delta E_{\mathrm{def}}$

In this equation, the interaction energy $\Delta E_{\text {int }}$ is the difference between the energy of the complex and the sum of energies of the monomers with the structures that take place in the complex. The deformation energy $\Delta E_{\text {def }}$ is the energy needed to deform the structure of monomers from their isolated state to that one they acquire in the complex. The $\Delta E_{\text {int }}$ of the inclusion compounds was further decomposed into encapsulation energy $\Delta E_{\mathrm{enc}}$ and hydrogen bonding energy $\Delta E_{\mathrm{HB}}$ according to equations $2-4$.

$\Delta E_{\text {int }}=E_{\text {cage } @ \mathrm{~A}}-\sum E_{\mathrm{m}}-E_{\mathrm{A}}$

$\Delta E_{\text {int }}=\left(E_{\text {cage } @ \mathrm{~A}}-E_{\text {cage }}-E_{\mathrm{A}}\right)+\left(E_{\text {cage }}-\sum E_{\mathrm{m}}\right)$

$\Delta E_{\text {int }}=\Delta E_{\mathrm{enc}}+\Delta E_{\mathrm{HB}}$

(4)

Here, $E_{\text {cage@A }}$ is the energy of the multimolecular inclusion compound (with $\mathrm{A}=\mathrm{Na}^{+}, \mathrm{Cl}^{-}, \mathrm{Ar}$ ), $E_{\mathrm{m}}$ is the energy of the monomers (either $\mathrm{M}$ or $\mathrm{CA}$ ) and $E_{\mathrm{A}}$ is the energy of the host; then $E_{\text {cage }}$ is the energy of the system without the guest, with the geometry of cage@A. All the interaction energies were corrected for the basis set superposition error (BSSE) withip, the counterpoise procedure of Boys and Berpardi.361039/C8CP07705C

The non-covalent interactions were analyzed within the framework of the Atoms in Molecules theory. ${ }^{9}$ Total electron densities were calculated at the same level of theory. The local properties at the bond critical points were computed using the AIMALL ${ }^{37}$ and Multiwfn ${ }^{38}$ programs. Molecular electrostatic potential surfaces were generated by mapping the electrostatic potential $V(r)$ on the electronic density surfaces. We considered an isosurface of $\rho(r)=0.001$ au, which was suggested by Bader et al. $^{39}$ and represents the effective molecular volume.

The interactions between the host and the isolated guests were also analyzed with the localized molecular orbital energy decomposition ${ }^{40}$ (LMOEDA) method at the BLYP-D3/6$311++G(d, p)$ level of theory, using the GAMESS ${ }^{41}$ quantum chemistry package. This method partitions the interaction energy into four components, according to equation 5 :

$\Delta E_{\text {int }}=\Delta E_{\text {ele }}+\Delta E_{\text {ex-rep }}+\Delta E_{\text {pol }}+\Delta E_{\text {disp }}$

where the term $\Delta E_{\text {ele }}$ describes the classical electrostatic interaction (Coulomb) of the occupied orbitals of one monomer with those of another monomer; $\Delta E_{\text {ex-rep }}$ is the attractive exchange component resulting from the Pauli exclusion principle and the interelectronic repulsion; $\Delta E_{\mathrm{pol}}$ accounts for polarization and charge transfer components; and $\Delta E_{\text {disp }}$ corresponds to the dispersion term.

All images were created with CYLview, ${ }^{42} \mathrm{VMD}^{43}$ and AIMAII ${ }^{37}$ softwares.

\section{Results and Discussion}

\section{Geometries and relative stabilities}

We started from the planar complexes. Then, the cage-like clusters were built by folding the planar ones in order to form cyclic quartets, and keeping the original hydrogen bonds $(\mathrm{H}-$ bonds). The structures of the systems are shown in Figure 1 , and the corresponding energies are displayed in Table 1 . All the cages assume a $C_{2}$ symmetry. When folding the planar systems into cyclic quartets, two extra $\mathrm{H}$-bonds are formed (or three in the case of $\mathrm{M}_{2} \mathrm{CA}_{2}$ ). Therefore, one may expect a stronger bonding energy in the later. However, there is an energy penalty related to the acceptor directionality of the $\mathrm{H}$-bond. ${ }^{44}$ Although the differences in interaction energies are around $5 \mathrm{kcal} \mathrm{mol}^{-1}$, $\Delta E_{\text {bond }}$ values show there is no extra stabilization. The only exception is the second cage of CA $\left(\mathrm{CA}_{4}-2\right)$, which is $4.8 \mathrm{kcal}$ $\mathrm{mol}^{-1}$ more stable than its planar counterpart. The formation of the cages also requires a deformation energy, which is almost cero for $C_{4}-2$ and relatively high for $M_{4}$ and $M_{2} C A_{2}$.

Finally, the Gibbs free energies of bonding show that the planar systems are by far the most stable ones. In the case of $\mathrm{CA}_{4}-2$, the planar and cage systems differ in just $0.8 \mathrm{kcal} \mathrm{mol}^{-1}$. Since this energy difference is very small, we can anticipate that the system will need the help of the guest to favor this cage-like cluster. In the next sections, we will show that the $\Delta G_{\text {bond }}$ for $\mathrm{CA}_{4}-2$ is notably enhanced due to the presence of ions. 


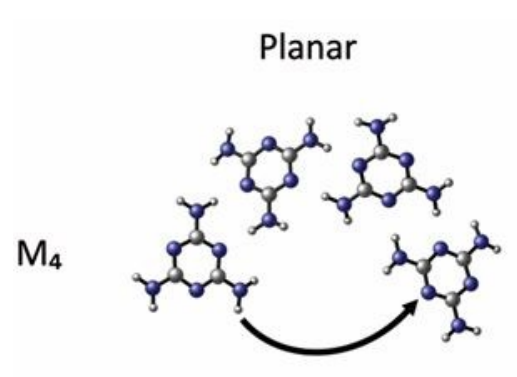

\section{Cage-shaped}
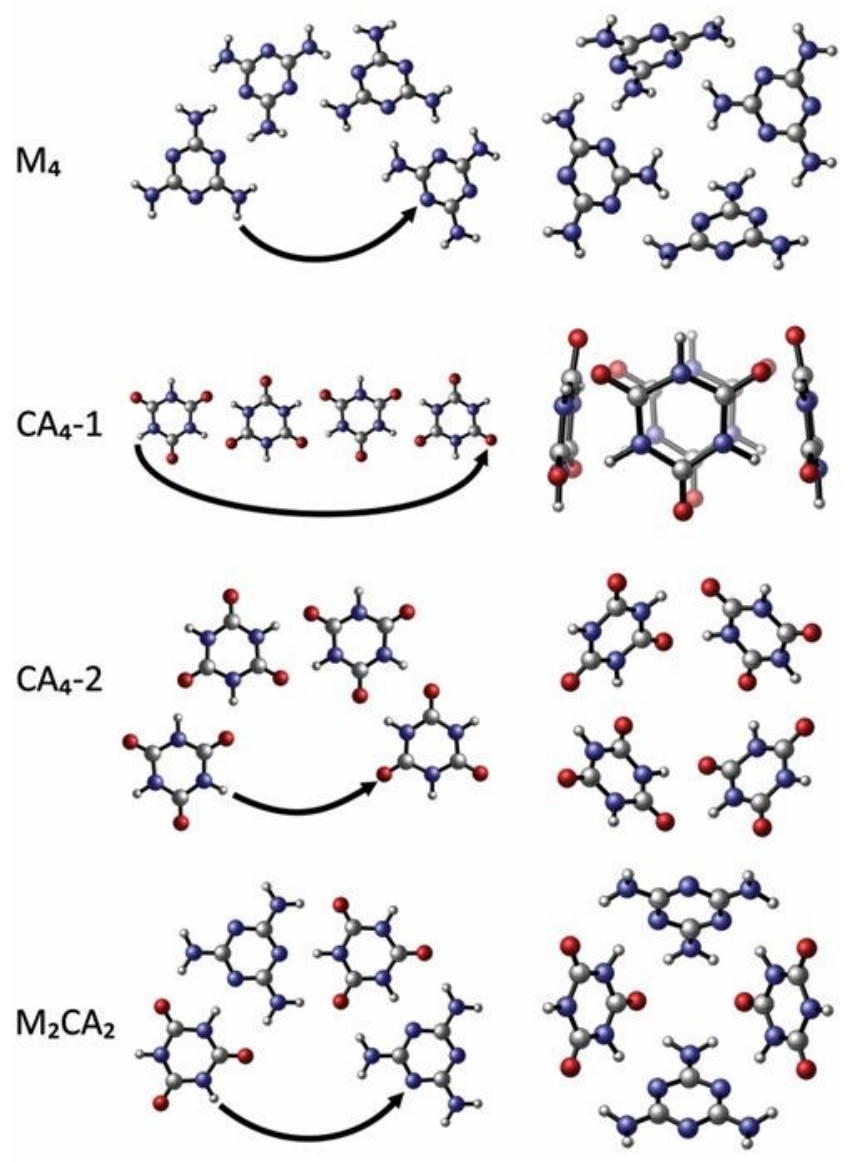

Fig. 1 Optimized geometries at $\omega B 97 X D / 6-311++G(d, p)$ level of theory. Black arrows indicate the folding of the planar systems.

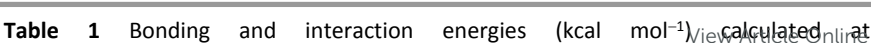
$\omega B 97 X D / 6-311++G(d, p)$ level of theory. DOl: 10.1039/C8CP07705C

\begin{tabular}{llrrrr}
\hline System & Type & $\Delta G_{\text {bond }}$ & \multicolumn{1}{c}{$\Delta E_{\text {bond }}$} & $\Delta E_{\text {def }}$ & $\Delta E_{\text {int }}$ \\
\hline $\mathrm{M}_{4}$ & Planar & 0,7 & -39.6 & 0.8 & -40.4 \\
& Cage & 6,9 & -40.1 & 4.6 & -44.7 \\
$\mathrm{CA}_{4}-1$ & Planar & $-6,9$ & -40.9 & 1.2 & -42.1 \\
& Cage & 0,2 & $-40,6$ & -0.5 & -40.1 \\
$\mathrm{CA}_{4}-2$ & Planar & $-6,4$ & -41.6 & 1.0 & -42.6 \\
& Cage & $-5,6$ & $-46,4$ & 0.7 & -47.1 \\
$\mathrm{M}_{2} \mathrm{CA}_{2}$ & Planar & $-21,4$ & -60.0 & 4.5 & -64.5 \\
& Cage & $-13,3$ & -60.8 & 7.4 & -68.2 \\
\hline
\end{tabular}

\section{Topology of the cavities}

All the cage-shaped quartets form regular cavities with a cup-like shape akin to that of calixarenes. From their molecular electrostatic potentials maps shown in Figure 2 ( $a$ and $b$ ), it can be seen that the inside is more positive than the outside surface. The $\mathrm{CA}_{4}-1$ cage creates the most positive cavity, followed by $\mathrm{CA}_{4}-2$, the mix complex of $\mathrm{M}_{2} \mathrm{CA}_{2}$ and $\mathrm{M}_{4}$. In order to gain more information of the cavities we then obtained sections of the electron densities $\rho(r)$, which are also plotted in Figure 2 (c). As shown in Figure $2, \mathrm{M}_{4}, \mathrm{CA}_{4}-2$ and $\mathrm{M}_{2} \mathrm{CA}_{2}$ display a cup-like shape, which are quite similar to some calixarenes. ${ }^{45,46}$ Furthermore, $\mathrm{CA}_{4}-1$ complex shows a cage-like cluster with a tubular cavity, alike that observed in the pillar[4]pyridinium molecular box. ${ }^{24}$ This structure suggests that linear molecules like $\mathrm{H}_{2}$ could fit inside the cavity.

Table 2 reports some meaningful topological parameters of $\mathrm{H}$-Bonds. That is, the electron density $\rho$ at the BCPs, that reflects the strength of a bond. The total energy density $H=G+V$, where $G$ and $V$ are the kinetic and potential energy densities respectively. Negative values of $H$ are usually associated to a covalence character. Nevertheless, when $H$ is negative the hydrogen bonds are stronger than those with positive values. ${ }^{34,47,48}$ The ellipticity $\varepsilon$, that measures the extent of the electron density within a plane containing the line path. In addition, it is a direct measure of the stability of a given bond, because it takes infinite large values preceding the coalescence of a ring critical point and a BCP. ${ }^{49}$ The delocalization $[\delta(A, B)]$ index, which is a measure of the number of electrons that are shared or exchanged between $A$ and B. Finally, the repulsive part of the local potential energy density $V_{\text {rep }}$ that accounts for electron-electron and nuclear-nuclear repulsion. 


\section{ARTICLE}

Table 2 Values of local topological properties (a.u.) at the bond critical points. ${ }^{\circ}$

\begin{tabular}{lllccccc}
\hline Complex & Type & Atoms & $\rho$ & $H$ & $\varepsilon$ & $\delta(\mathrm{H}, \mathrm{N} / \mathrm{O})$ & $V_{\text {rep }}$ \\
\hline $\mathrm{M}_{4}$ & Planar & $\mathrm{H} \cdots \mathrm{N}$ & 0.029 & 0.001 & 0.073 & 0.096 & 0.888 \\
& Cage & $\mathrm{H} \cdots \mathrm{N}$ & 0.024 & 0.001 & 0.093 & 0.081 & 0.782 \\
$\mathrm{CA}_{4}-1$ & Planar & $\mathrm{H} \cdots \mathrm{O}$ & 0.031 & 0.001 & 0.033 & 0.087 & 0.914 \\
& Cage & $\mathrm{H} \cdots \mathrm{O}$ & 0.023 & 0.002 & 0.026 & 0.068 & 0.777 \\
$\mathrm{CA}_{4}-2$ & Planar & $\mathrm{H} \cdots \mathrm{O}$ & 0.032 & 0.001 & 0.032 & 0.089 & 0.985 \\
& Cage & $\mathrm{H} \cdots \mathrm{O}_{\text {up }}{ }^{b}$ & 0.022 & 0.003 & 0.041 & 0.064 & 0.695 \\
& & $\mathrm{H} \cdots \mathrm{O}_{\text {down }}{ }^{c}$ & 0.032 & 0.001 & 0.032 & 0.086 & 1.088 \\
$\mathrm{M}_{2} \mathrm{CA}_{2}$ & Planar & $\mathrm{H} \cdots \mathrm{O}$ & 0.025 & 0.002 & 0.051 & 0.076 & 0.759 \\
& & $\mathrm{H} \cdots \mathrm{N}$ & 0.045 & -0.007 & 0.065 & 0.138 & 1.507 \\
& Cage & $\mathrm{H} \cdots \mathrm{O}_{\text {up }}$ & 0.018 & 0.002 & 0.078 & 0.056 & 0.533 \\
& & $\mathrm{H} \cdots \mathrm{N}_{\text {middle }}{ }^{d}$ & 0.033 & -0.001 & 0.096 & 0.108 & 1.188 \\
& & $\mathrm{H} \cdots \mathrm{O}_{\text {down }}$ & 0.021 & 0.002 & 0.092 & 0.062 & 0.744 \\
\hline
\end{tabular}

${ }^{a}$ Due to symmetry reasons, average values are shown. ${ }^{b}$ The sub index up corresponds to the average values of the largest opening. ${ }^{c}$ The sub index down corresponds to the average values of the smallest opening. ${ }^{d}$ Middle corresponds to hydrogen bonds positioned at the middle of the cup-like structure.

(a)
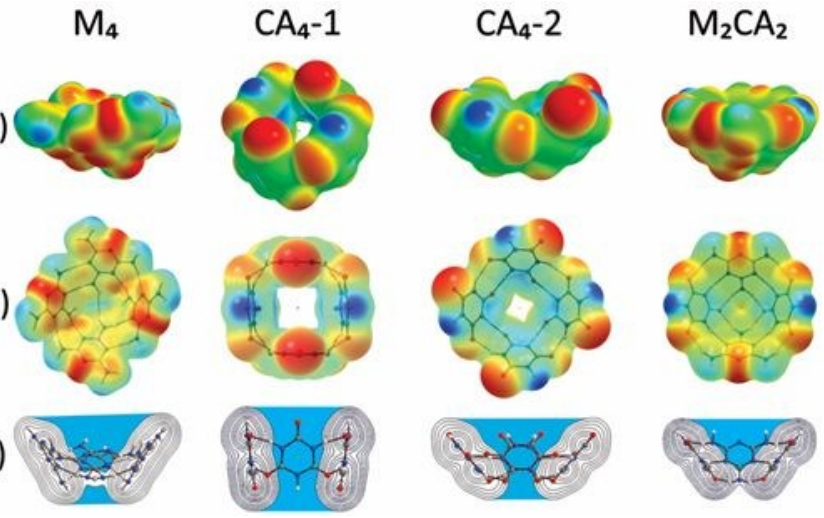

Fig. 2 (a) Side views of molecular electrostatic potentials (MEPs) maps on the 0.001 a.u. electron density isosurfaces. (b) Top views of MEPs. The values of the MEP vary between $-31 \mathrm{kcal} \mathrm{mol}^{-1}$ (red) and $56 \mathrm{kcal} \mathrm{mol}^{-1}$ (blue). (c) Contour plots of cage-shaped complexes superimposed to molecular graphs. The free space is colored at light blue.

When going from the planar systems to the cage-like structures, $\mathrm{H}$-Bonds undergo an important bending. This deformation has an impact on the acceptor directionality, ${ }^{50}$ and it is clearly reflected in their topological values (see Table 2). According to $\rho$, the strength of the bond decreases with the bending along with a decrease in $\delta(\mathrm{H}, \mathrm{N} / \mathrm{O})$. The ellipticity also increases, except in $\mathrm{CA}_{4}-1$. The fact that the cup-like structure of $\mathrm{CA}_{4}-2$ is more stable than the planar form can be undoubtedly understood by looking the topological parameters. The $\mathrm{CA}_{4}-2$ cup-shaped complex forms $8 \mathrm{H}$-bonds, four within the largest opening $\left(\mathrm{H} \cdots \mathrm{O}_{\mathrm{up}}\right)$ and four below it $\left(\mathrm{H} \cdots \mathrm{O}_{\text {down }}\right)$, having different topological properties. As can be seen from Table 2, the bending does not significantly affect the $\mathrm{H}$-bond properties of the smallest opening, if we compare them with the planar system. Therefore, the two extra $\mathrm{H}$-bonds that are formed in the cage complex are enough to compensate the decrease in interaction energy do to the directionality.

\section{Encapsulation effect}

As was shown in the previous section, all the cage-shaped complexes form regular cavities that could host atomic species, or even linear molecules. Therefore, we put them to test with ionic and neutral species like sodium, chloride and argon. All the systems were fully optimized, and those who kept their original shapes are reported. Table 3 shows the bonding analysis of the multimolecular inclusion complexes. Gibbs free energies and bonding energies are more stabilizing with the presence of the hosts, except for $\mathrm{M}_{4} @ A r$ and and $\mathrm{CA}_{4}-1 @ A r$. Among all the complexes, just $\mathrm{CA}_{4}-2$ can host a sodium cation and keep its original shape, being the encapsulation energy the greatest one. The other cages $\left(\mathrm{M}_{4}, \mathrm{CA}_{4}-1\right.$ and $\left.\mathrm{M}_{2} \mathrm{CA}_{2}\right)$ are fully deformed with the presence of $\mathrm{Na}^{+}$. This is because the coordinating groups of $\mathrm{CA}_{4}-2$ ( $\mathrm{C}=\mathrm{O}$ groups) converge to the metal in the complex, alike guanine quartets. ${ }^{51}$ Whilst in the other cases, both endocyclic nitrogen's and carbonyl groups are not adequately orientated to coordinate the metal. One should also take into account that the triazine rings cannot interact with metals via the $\pi$ cloud.

Concerning chloride, the greatest $\Delta E_{\text {enc }}$ is shown for $C A_{4}-1$, followed by $C A_{4}-2, M_{2} C A_{2}$ and $M_{4}$. This trend suggests that the triazine skeleton of $\mathrm{CA}$ is better than the melamine one to capture anions, which could be used for synthesizing new heterocalixarenes. In this context, Frontera et al. have already shown experimental evidence of chloride- $\pi$ interactions in CA crystals. ${ }^{23}$ The deformation energies are also more favorable for 
CA complexes. For the sake of comparison, we computed the corrected interaction energy ( $\omega B 97 X D / 6-$ $311++G(d, p) / / B P 86 / T Z 2 P)$ for an heterocalixarene-chloride complex recently reported by Caramori et al. ${ }^{52}$ (see compound 1. $\mathrm{Cl}^{-}$). The complex has an encapsulation energy of $-31.8 \mathrm{kcal}$ $\mathrm{mol}^{-1}$ (BP86/TZ2P energy ${ }^{52}$ is $-37.6 \mathrm{kcal} \mathrm{mol}^{-1}$ ), which is very close to those informed in Table 3 , and even smaller. Finally, since the second cage of CA can host both ions $\mathrm{Na}^{+}$and $\mathrm{Cl}^{-}$, one may think that this system could host both ions at the same time. Indeed, we optimized the $\mathrm{CA}_{4}-2$ system with the $\mathrm{NaCl}$ ionic pair and the complex keeps its original shape (see Figure S1). The $\Delta E_{\text {enc }}$ is $-55.7 \mathrm{kcal} \mathrm{mol}^{-1}$ (value not informed in the Table), and the $\Delta E_{\text {def }}$ is even lower than for the isolated ions $(1.6 \mathrm{kcal}$ $\mathrm{mol}^{-1}$ ).

When an argon atom is placed within the cavity, the most favorable values are, again, those for CA complexes, as shown in Table 3. That is, high encapsulation energies and low deformation energies.

Table 3 Bonding analysis ( $\mathrm{kcal} \mathrm{mol}^{-1}$ ) of multimolecular inclusion compounds obtained at $\omega B 97 X D / 6-311++G(d, p)$ level of theory.

\begin{tabular}{llrrrrrr}
\hline Complex & Guest & $\Delta G_{\text {bond }}$ & $\Delta E_{\text {bond }}$ & $\Delta E_{\text {def }}$ & \multicolumn{1}{c}{$\Delta E_{\text {int }}$} & \multicolumn{1}{c}{$\Delta E_{\mathrm{HB}}$} & $\Delta E_{\text {enc }}$ \\
\hline $\mathrm{M}_{4}$ & $\mathrm{Cl}^{-}$ & -8.3 & -66.6 & 12.1 & -78.7 & -44.1 & -34.5 \\
& $\mathrm{Ar}$ & 10.3 & -44.1 & 4.3 & -48.4 & -45.0 & -3.4 \\
$\mathrm{CA}_{4}-1$ & $\mathrm{Cl}^{-}$ & -40.4 & -92.0 & 2.3 & -94.3 & -40.3 & -54.0 \\
& $\mathrm{Ar}$ & 2.0 & -45.0 & -1.1 & -43.9 & -40.1 & -3.8 \\
$\mathrm{CA}_{4}-2$ & $\mathrm{Na}^{+}$ & -51.2 & -102.6 & 6.6 & -109.2 & -44.8 & -64.3 \\
& $\mathrm{Cl}^{-}$ & -37.0 & -88.3 & 3.1 & -91.3 & -45.2 & -46.2 \\
& $\mathrm{Ar}$ & -2.6 & -49.7 & 0.2 & -49.9 & -47.1 & -2.8 \\
$\mathrm{M}_{2} \mathrm{CA}_{2}$ & $\mathrm{Cl}^{-}$ & -39.0 & -97.6 & 10.9 & -108.4 & -66.8 & -41.6 \\
& $\mathrm{Ar}$ & -9.6 & -64.9 & 7.0 & -71.9 & -68.4 & -3.5 \\
\hline
\end{tabular}

\section{Confined interactions}

View Article Online

LMOEDA Before evaluating the forces that take part in the encapsulation, we must know the nature of the interactions between the atomic species and the isolated triazines. Therefore, we computed a potential energy scan by varying the distance $(\boldsymbol{r})$ between $\mathrm{Cl}^{-} / \mathrm{Ar}$ and the triazine ring center. The systems were optimized with $C_{3}$ symmetry, and the $r$ distance was varied from $2.7 \AA$ to $3.4 \AA$ with a $0.05 \AA$ step (15 optimizations). We then decomposed the interaction energy in every step and the profile for chloride is plotted in Figure 3 (see energy profile for argon in Figure S2).

At first glance, chloride interacts more strongly with CA than $M$ along all the scanned distance. At the equilibrium geometry, the interaction energy with $\mathrm{M}$ is $-8.7 \mathrm{kcal} \mathrm{mol}^{-1}$ and $-19.7 \mathrm{kcal}$ $\mathrm{mol}^{-1}$ with CA. Both values are in very good accordance with previous MP2 computations for the same/similar systems. While Berryman et al. ${ }^{53}$ have found a $\Delta E_{\text {bond }}=-8.33 \mathrm{kcal} \mathrm{mol}^{-1}$ for a triazine ring (without $-\mathrm{NH}_{2}$ groups) at the MP2/aug-ccpVDZ level of theory; Frontera et $a .^{23}$ have obtained a $\Delta E_{\text {bond }}$ of $-22.81 \mathrm{kcal} \mathrm{mol}^{-1}\left(\Delta E_{\text {bond }}=-16.45 \mathrm{kcal} \mathrm{mol}^{-1}\right.$ with BSSE) for $\mathrm{CA} @ \mathrm{Cl}^{-}$complex at the MP2(full)/6-31++G** level of theory. The profile of the energy components indicates that the electrostatic part is the dominant factor of the interaction energy. In addition, the interaction between $\mathrm{Cl}^{-}$and CA has larger charge transfer and dispersion components. These results are in agreement with the trends of encapsulation energies, reaffirming therefore, the fact that the CA skeleton is a better candidate for synthesizing molecular hosts based on triazines. 


\section{ARTICLE}
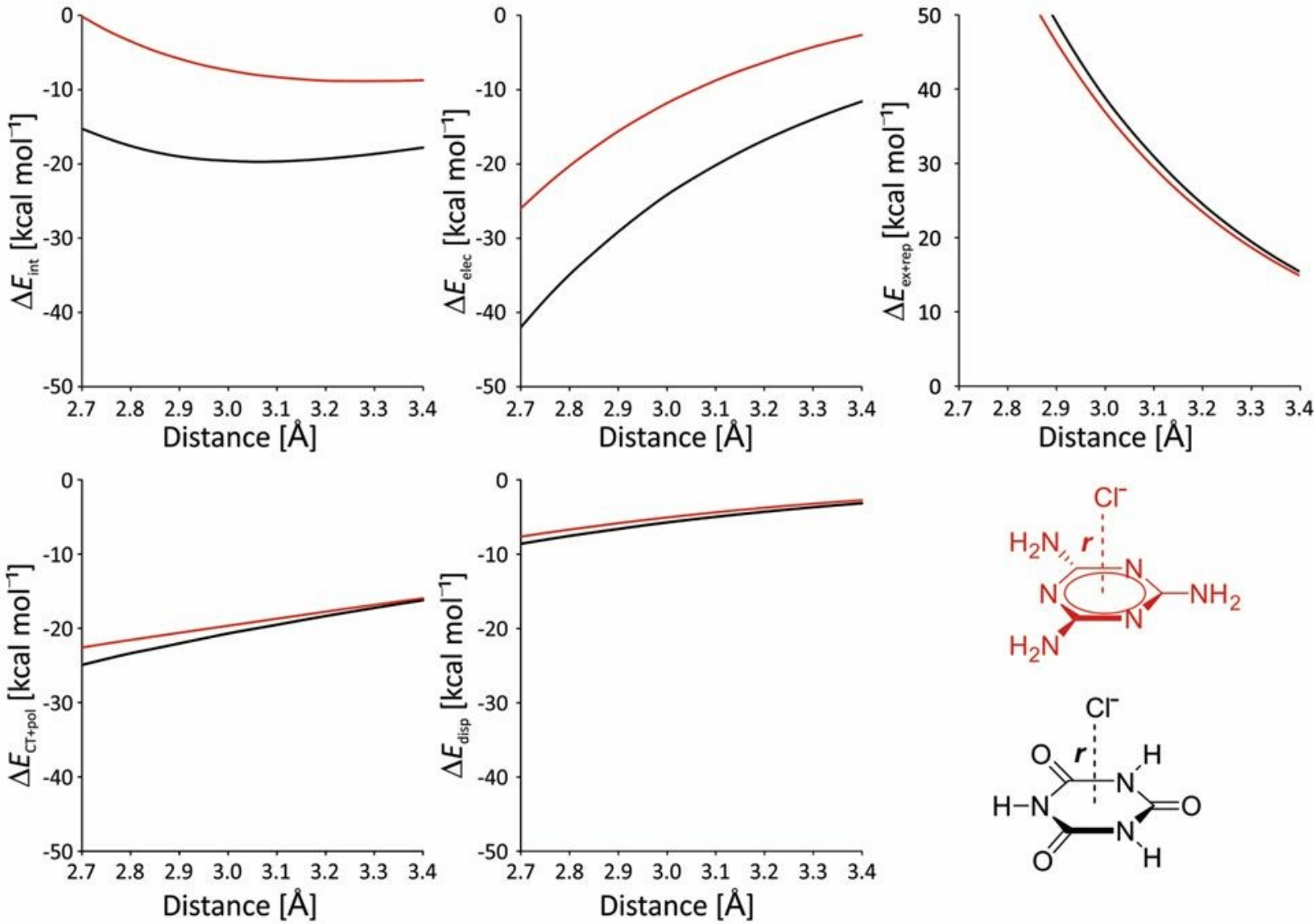

Fig. 3 Variation of LMOEDA energy components as a function of $r$. Chemical structures of the scanned systems are shown, where $r$ is the scanned distance.

Concerning the interactions with argon, the differences in interaction energies are negligible (the energy profiles are shown in the supporting information).

When $\mathrm{M} \cdots \mathrm{Cl}^{-} / \mathrm{Ar}$ and $\mathrm{CA} \cdots \mathrm{Cl}^{-} /$Ar interactions are confined in the cavity, their nature change drastically. Table 4 collects the LMOEDA analysis of all complexes. In general, the attractive nature of the encapsulation is mostly explained by the charge transfer component. For instance, the interaction of chloride with CA goes from $46 \%$ electrostatic in the non-confined state to $5.6 \%$ in the $\mathrm{CA}_{4}-1$ complex. The other complexes show repulsive electrostatic interactions, and the trend follows observation of Figure $2\left(\mathrm{CA}_{4}-2<\mathrm{M}_{4}<\mathrm{M}_{2} \mathrm{CA}_{2}\right)$. The fact that the $\mathrm{M}_{4} @ \mathrm{Cl}^{-}$cage shows a larger charge transfer contribution is due to the presence of $\mathrm{N}-\mathrm{H} \cdots \mathrm{Cl}^{-} \mathrm{H}$-bonds that hold the anion. Moreover, the Pauli repulsion is again larger for the systems with $\mathrm{M}$, and the dispersion component is almost the same for all the systems.

All of these interaction energy components lead us to think that the CA molecule will be the best choice. Not only because an improved interaction energy with the ions but also because this fact will most likely guide the process to the target system. In the beginning of the assembly, the process will be under the control of the electrostatic energy. When the cage is formed, the ion will be held by stronger orbital interactions than in the free state. Of course, one has to think that all the cages should be equipped with functional groups to improve the stabilization. They can act like "arms" ${ }^{23}$ or "tweezers" 54 in order to assist in holding the guest with extra interactions. In order to pre-induce complexation, ${ }^{20}$ another approach could be the joint attachment between two or more monomers. ${ }^{22,55}$ 
Table 4 Energy decomposition analysis (in $\mathrm{kcal} \mathrm{mol}^{-1}$ ) of equilibrium geometries obtained at BLYP-D3/6-311++G(d,p)

\begin{tabular}{llrrrrr}
\hline Complex & Guest & \multicolumn{1}{c}{$\Delta E_{\text {ele }}$} & $\Delta E_{\text {ex-rep }}$ & \multicolumn{1}{c}{$\Delta E_{\text {pol }}$} & \multicolumn{1}{c}{$\Delta E_{\text {disp }}$} & \multicolumn{1}{c}{$\Delta E_{\text {int }}$} \\
\hline $\mathrm{M}$ & $\mathrm{Cl}^{-}$ & -2.90 & 13.08 & -16.12 & -2.81 & -8.74 \\
& $\mathrm{Ar}$ & 5.69 & 2.90 & -8.62 & -1.35 & -1.38 \\
$\mathrm{CA}$ & $\mathrm{Cl}^{-}$ & -21.52 & 26.98 & -19.93 & -5.23 & -19.71 \\
& $\mathrm{Ar}$ & 6.11 & 2.94 & -9.16 & -1.39 & -1.51 \\
$\mathrm{M}_{4}$ & $\mathrm{Cl}^{-}$ & 5.58 & 63.46 & -93.33 & -11.45 & -35.45 \\
& $\mathrm{Ar}$ & 48.46 & 8.94 & -58.03 & -3.93 & -4.55 \\
$\mathrm{CA}_{4}-1$ & $\mathrm{Cl}$ & -4.92 & 34.76 & -75.35 & -7.71 & -53.22 \\
& $\mathrm{Ar}$ & 44.79 & 10.1 & -55.82 & -4.63 & -5.56 \\
$\mathrm{CA}_{4}-2$ & $\mathrm{Cl}^{-}$ & 0.03 & 31.73 & -70.88 & -6.99 & -46.11 \\
& $\mathrm{Ar}$ & 42.78 & 6.49 & -50.31 & -3.02 & -4.05 \\
$\mathrm{M}_{2} \mathrm{CA}_{2}$ & $\mathrm{Cl}^{-}$ & 7.78 & 45.53 & -86.24 & -8.61 & -41.46 \\
& $\mathrm{Ar}$ & 51.65 & 9.40 & -61.78 & -4.18 & -4.91 \\
\hline
\end{tabular}

QTAIM When either chloride or argon is approached to the triazine ring, interactions with the $\pi$ system are expected. ${ }^{52,56}$ In the framework of the QTAIM, a bond path is a line of maximum electron density that links a pair of nuclei ${ }^{57,58}$ at the equilibrium geometry. When looking the $L(r)$ function $\left(-\nabla^{2} \rho\right)$ of $\mathrm{M}$ and CA (Figure 4), a nonbonding charge concentration (NCC) over $\mathrm{N}$ atoms and a hole over $\mathrm{C}$ can be observed. Note that the NCCs correspond to the Lewis model of lone pairs. In the triazine ring of $\mathrm{CA}$, the lone pairs of $\mathrm{N}$ appear delocalized. Therefore, BCPs between either $\mathrm{Cl}^{-}$or $\mathrm{Ar}$ and $\mathrm{N}$ atoms would be likely to be present. Figure 5 shows the molecular graphs of complexes $\mathrm{M} \cdots \mathrm{Cl}^{-} / \mathrm{Ar}$ and $\mathrm{CA} \cdots \mathrm{Cl}^{-} / \mathrm{Ar}$, in which $\mathrm{BCPs}$ between $\mathrm{Cl}^{-} / \mathrm{Ar}$ and $\mathrm{N}$ atoms are observed; and Table 5 reports the average properties of those BCPs. The reported values are characteristic of weak closed-shell interactions: low values of $\rho$, positive laplacian $\nabla^{2} \rho$ and $H \approx 0$. Since $\rho$ and $\delta($ A.B $)$ are good indicators of the bond strength, their values are in line with the interaction energies. In addition, $V_{\text {rep }}$ is more repulsive for $\mathrm{CA} \cdots \mathrm{Cl}^{-}$, as was shown in the previous section. Observations regarding Argon indicate there are no significant differences between $M$ and CA.

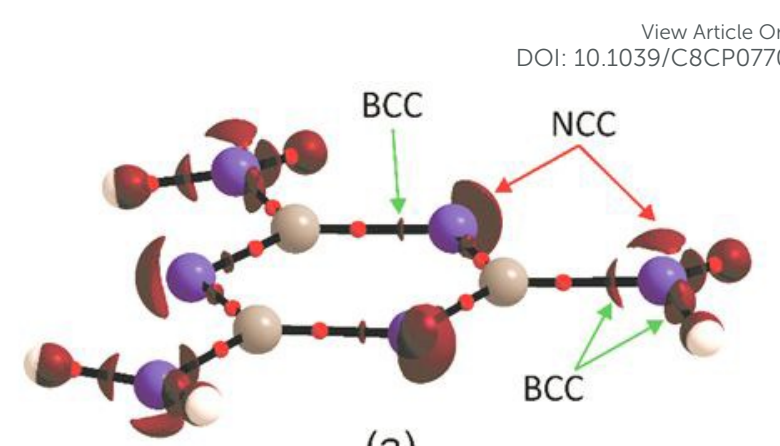

(a)

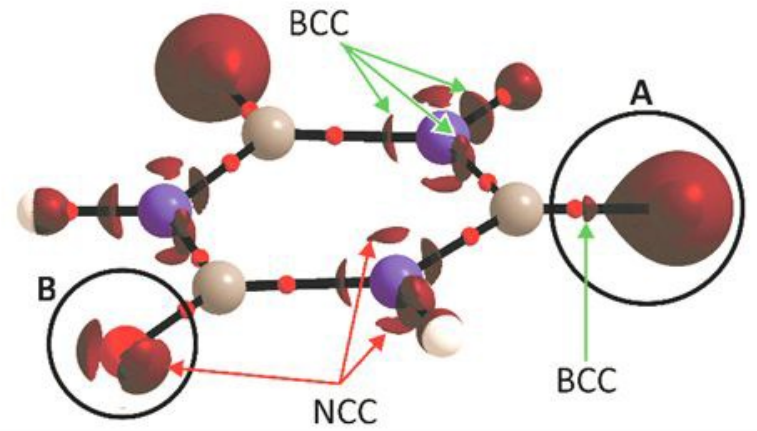

(b)

Fig. 4 Three-dimensional isosurfaces of $L(r)=1.5$ a.u. for (a) melamine and (b) cyanuric acid. Circles $\mathbf{A}$ and $\mathbf{B}$ correspond to $L(r)=1.03$ and 3.0 respectively. Bonding $(B C C)$ and nonbonding charge concentrations (NCC) are indicated with arrows.

Table 5 Local topological properties at $\mathrm{N} \cdots \mathrm{Cl}^{-} /$Ar bond critical points ${ }^{a}$ (a.u.)

\begin{tabular}{cccccccc}
\hline Complex & Atoms & $\rho$ & $\nabla^{2} \rho$ & $\mathrm{H}$ & $\varepsilon$ & $\delta(\mathrm{A} . \mathrm{B})$ & $V_{\text {rep }}$ \\
\hline $\mathrm{CA} \cdots \mathrm{Cl}^{-}$ & $\mathrm{N} \cdots \mathrm{Cl}^{-}$ & 0.009 & 0.029 & 0.001 & 2.343 & 0.064 & 0.189 \\
$\mathrm{CA} \cdots \mathrm{Ar}$ & $\mathrm{N} \cdots \mathrm{Ar}$ & 0.003 & 0.011 & 0.001 & 0.370 & 0.017 & 0.055 \\
$\mathrm{M} \cdots \mathrm{Cl}^{-}$ & $\mathrm{N} \cdots \mathrm{Cl}^{-}$ & 0.006 & 0.016 & 0.001 & 3.416 & 0.040 & 0.104 \\
$\mathrm{M} \cdots \mathrm{Ar}$ & $\mathrm{N} \cdots \mathrm{Ar}$ & 0.003 & 0.011 & 0.001 & 1.216 & 0.015 & 0.052 \\
\hline
\end{tabular}

${ }^{a}$ Average values of bond critical points. 
M

CA
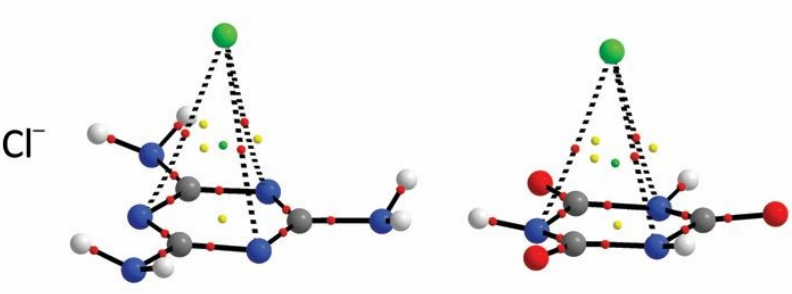

$\operatorname{Ar}$
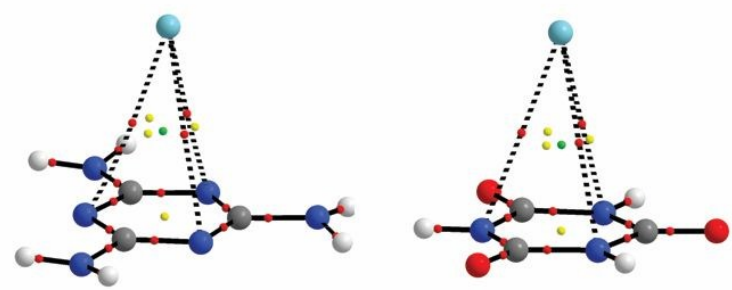

Fig. 5 Molecular graphs of $\mathrm{M} \cdots \mathrm{Cl}^{-} / \mathrm{Ar}$ and $\mathrm{CA} \cdots \mathrm{Cl}^{-} / \mathrm{Ar}$ complexes. Small red dots are $\mathrm{BCP}$ yellow dots are ring critical points and green dots are cage critical points.

It is worth to note that some meaningful QTAIM parameters ( $\rho$, ESP, $V_{\text {rep }}$ and charge transfer) are straight related to LMOEDA terms $\left(\Delta E_{\text {int }}, \Delta E_{\text {ele }}, \Delta E_{\text {ex-rep }}, \Delta E_{\text {pol }}\right.$ and $\left.\Delta E_{\text {disp }}\right)$, as shown in Figures S3-S6 in supporting information. These relationships were obtained by computing the local topological properties over the scanned systems, which were discussed above. For instance, among other relationships between EDA components and AIM parameters, ${ }^{59,60}$ it has been shown that there is a linear relationship between $\rho$ and the interaction energy. ${ }^{48,61}$ However, we found herein a quadratic relationship between these two parameters. In addition, the sum of the ESPs at the BCPs vs. $\triangle E_{\text {ele, }}$ and the charge transfer obtained by QTAIM vs. $\Delta E_{\mathrm{pol}}$ were found to be linearly correlated for both $\mathrm{CA}^{\mathrm{N}} \cdot \mathrm{Cl}^{-}$and $\mathrm{M} \cdots \mathrm{Cl}^{-}$systems. In the case of Argon, the charge transfer values obtained with the QTAIM fails to describe its behavior. Previous studies on Voronoi Deformation Densities have shown that Bader's charges fail to describe some systems. ${ }^{62}$ Nevertheless, according to those relationships, the topological properties can be used to monitor either the strength, electrostatic and repulsive features of the interactions.

Now that we have identified the nature of the interactions between the atomic species and $\mathrm{M}$ and $\mathrm{CA}$ isolated rings, we analyze the situations within the cavities. Figure 6 shows the molecular graphs of the multimolecular inclusion compounds, and topological properties of the inclusion interactions are reported in Table S1 (supporting information). The presence of BCPs between the multimolecular hosts and the guests clearly show the encapsulation effect. They show typical values of weak closed-shell interactions. The values of $\rho(\mathrm{BCP})$ are within the range of $0.004-0.023$ a.u. for the systems with chloride and
0.003-0.004 a.u. for the systems with argon. The H-Bonds that keep the cavity are also intact, and their topological properties do not change significantly (see Table S2). When the $\mathrm{M} \cdots \mathrm{Cl}-/ \mathrm{Ar}$ and $\mathrm{CA} \cdots \mathrm{Cl}^{-} / \mathrm{Ar}$ interactions are confined, their topological properties display a different behavior. These changes are consistent with those observed in the LMOEDA analysis. For example, the interactions with chloride are weaker than those of chloride with the isolated rings. Nevertheless, the presence of multiple bond paths increases the interaction energy. Interestingly, in some cases, the BCPs appear between $\mathrm{C}$ atoms and the guests, instead of $\mathrm{N}$ (e.g., $\mathrm{CA}_{4}-2$ ). In the case of $\mathrm{M}_{4} @ \mathrm{Cl}^{-}$, the anion is also held by $\mathrm{N}-\mathrm{H} \cdots \mathrm{Cl}^{-} \mathrm{H}-$ Bonds. It is also interesting to point out that, in most of the cases, the host-guest $\mathrm{N} \cdots \mathrm{Cl}^{-}$ interactions show significant lower values of ellipticity $(\varepsilon)$ when they are compared with the non-confined values. This might indicate the interactions are more stable within the cage. Furthermore, when comparing $\mathrm{CA}_{4}-1 @ \mathrm{Cl}^{-}$and $\mathrm{CA}_{4}-2 @ \mathrm{Cl}^{-}$the sum of $\rho$ and $\delta$ (A.B) are in line with the encapsulation energies $\Delta E_{\text {enc }}$. The repulsion $\left(\sum V_{\text {rep }}\right)$ is also greater for the $\mathrm{CA}_{4}-1 @ \mathrm{Cl}^{-}$ complex, also in agreement with values of Table 4. Even though we cannot address strong conclusion regarding the character of the interactions, what is evident herein are the differences between the confined and non-confined states. The multimolecular hosts produce a chemical space with an environment that is totally different from the separate triazine rings.

On the other hand, the $\mathrm{CA}_{4}-2$ cage is the only system that can capture $\mathrm{Na}^{+}$without losing the original cup structure. The cation is tetracoordinated, and the BCPs show values that are characteristic of closed-shell interactions as well: low values of $\rho$, and positive values of $\nabla^{2} \rho$ and $H$. According to Bader, this type of interaction cannot be classified as a metal coordination (relatively low values of $\rho$, small negative values for $H$ with $G / \rho$ $\cong 1$ and small positive values for values $\nabla^{2} \rho$ ). ${ }^{63}$ It should also be mentioned that barbituric acid and their derivatives have already been used to coordinate metals and cations in supramolecular compounds. ${ }^{64}$ In some crystals of barbituric acid ${ }^{65}$ and 5,5-diethylbarbiturato, ${ }^{66}$ for example, $\mathrm{Na}^{+}$and $\mathrm{K}^{+}$ions have been observed to be hexa- $\left(\mathrm{NaO}_{6}\right)$ and tetra-coordinated $\left(\mathrm{O}_{2}-\mathrm{K}-\mathrm{O}_{2}-\mathrm{K}-\mathrm{O}_{2}\right)$ by the $\mathrm{C}=\mathrm{O}$ groups. Furthermore, the same system $\left(\mathrm{CA}_{4}-2 @ \mathrm{Na}^{+}\right)$can simultaneously hold chloride, that is, $\mathrm{CA}_{4}-2 @ \mathrm{NaCl}$. Its molecular graph (Figure 7), shows a different topology for chloride. In this complex, the anion is pushed down the cavity because of the presence of the cation. Consequently, the anion interacts less with the $\pi$ cloud of CA. Note that the encapsulation energies for the separate ions $\mathrm{Na}^{+}$and $\mathrm{Cl}^{-}$are -64.3 and $-46.2 \mathrm{kcal} \mathrm{mol}^{-1}$, respectively (Table 3 ). However, the encapsulation energy of the ionic pair is $-55.7 \mathrm{kcal} \mathrm{mol}^{-1}$. This 
suggest that the whole encapsulation energy of $\mathrm{NaCl}$ might just come from the coordination of $\mathrm{Na}^{+}$counter ion.

\section{$\mathrm{M}_{4}$}

$\mathrm{CA}_{4}-1$

$\mathrm{Na}^{+}$

$\mathrm{Cl}^{-}$
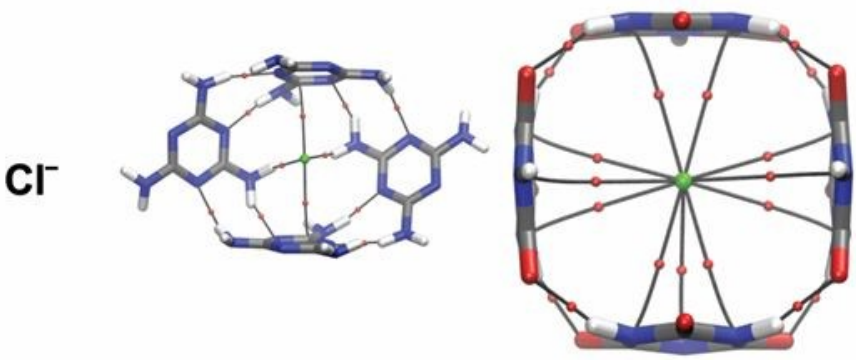

$\mathrm{CA}_{4}-2$

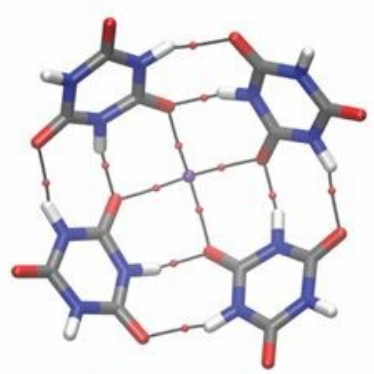

Ar
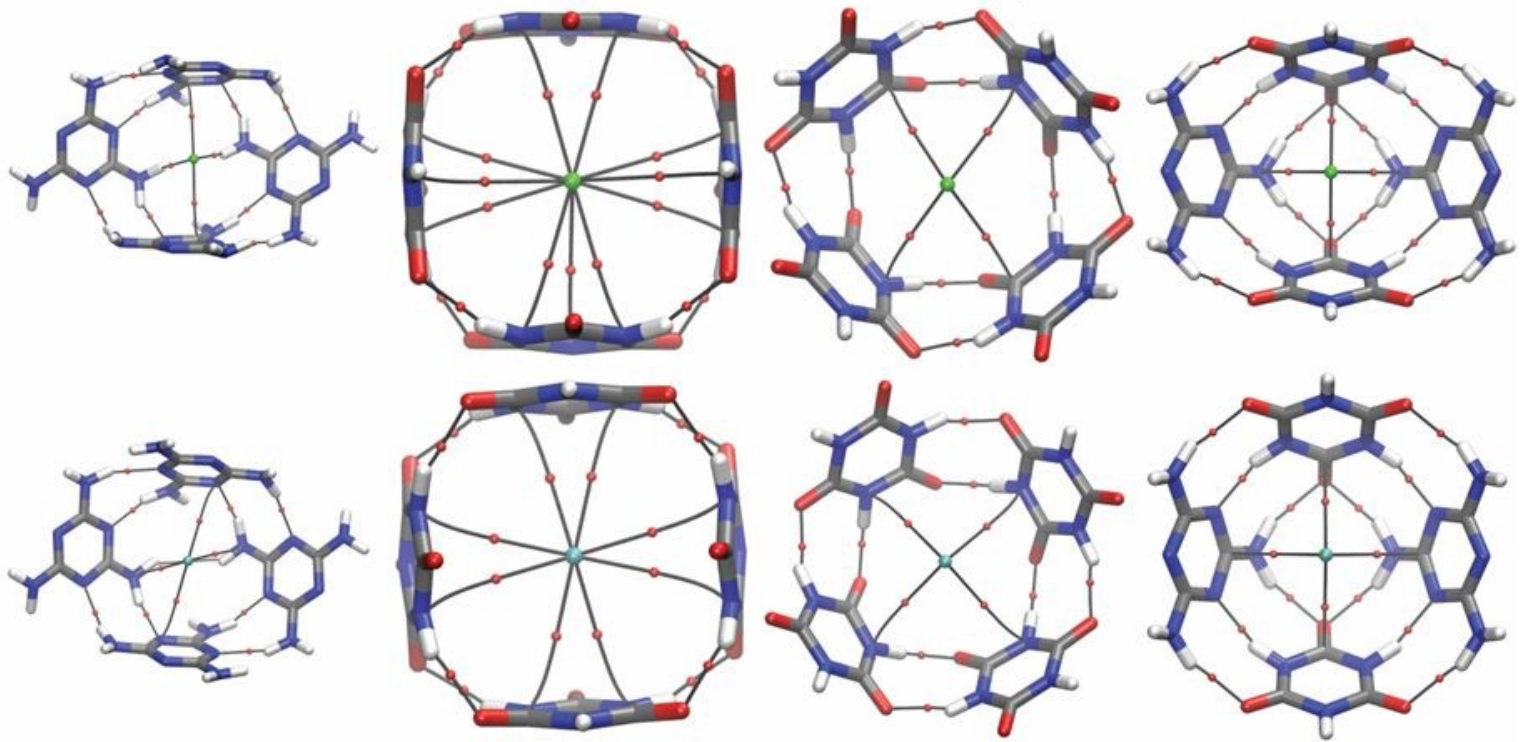

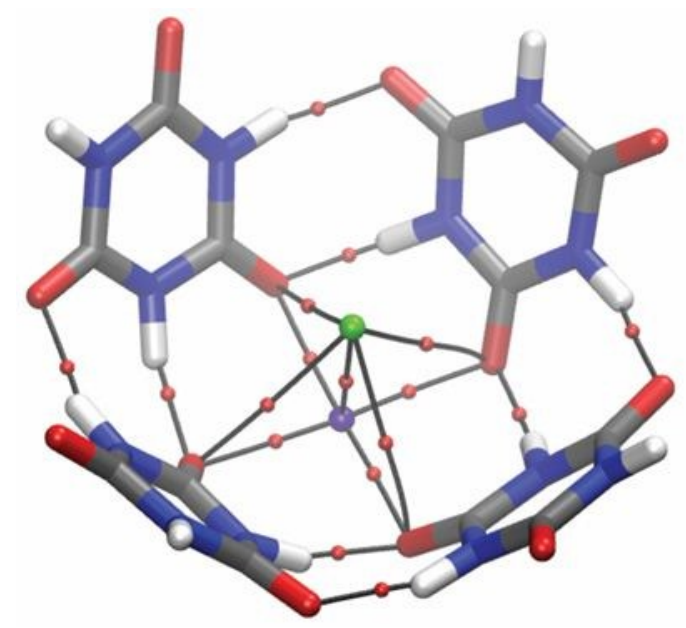

Fig. 7 Molecular graph of CA cage-shaped cluster acting as a dual receptor of sodium cation and chloride.

\section{Conclusions}

In this work, we have conducted a DFT-D analysis over a set of multimolecular inclusion compounds based on M and CA. Our study has shown that these molecules are able to form confined cavities alike calixarenes with the ability to host small atomic species. Whilst the cavity is created by hydrogen bonds, in most of the cases the guest species are encapsulated due to the interactions with the $\pi$ systems of melamine and cyanuric acid. Nevertheless, melamine can retain the anion with its amino groups $\left(\mathrm{N}-\mathrm{H} \cdots \mathrm{Cl}^{-}\right)$, while cyanuric acid can coordinate cations with its keto groups $\left(\mathrm{C}=\mathrm{O} \cdots \mathrm{Na}^{+}\right)$.

Our bonding analysis suggests that only one cage-shaped supramolecule of CA is more stable than its open structure by $\sim 5 \mathrm{kcal} \mathrm{mol}^{-1}$. In the other cases, the extra hydrogen bonds, which are created in the cyclic complexes, are not enough to compensate the weakening of the interactions due to the bending. The triazine skeleton of CA was also shown to be more robust to capture an ionic guest. In addition, our computations suggest that CA could act as a dual receptor of ionic pairs. Therefore, with proper covalent modifications, CA seems to be the most versatile building block for synthesizing supramolecular inclusion compounds via hydrogen bonds. Nevertheless, the other cage-shaped structures could serve as model sets for constructing new heteromolecular hosts. 


\section{Conflicts of interest}

There are no conflicts to declare.

\section{Acknowledgements}

The authors gratefully acknowledges the financial support from the Secretaría de Ciencia y Tecnología, Universidad Tecnológica Nacional, Facultad Regional Resistencia. A.N.P. thanks the National Scientific and Technical Research Council (CONICET), Argentina, for a doctoral fellowship. N.M.P. is a CONICET career researcher.

\section{Notes and references}

1 J. L. Atwood and J. W. Steed, Eds., Encyclopedia of Spramolecular Chemistry. Vol 1, CRC Press, Boca Raton, 2004.

2 M. Yoshizawa, J. K. Klosterman and M. Fujita, Functional molecular flasks: new properties and reactions within discrete, self-assembled hosts, Angew. Chem., Int. Ed., 2009, 48, 34183438.

3 O. Dumele, N. Trapp and F. Diederich, Halogen Bonding Molecular Capsules, Angew. Chem., Int. Ed., 2015, 54, 1233912344.

4 B. T. Birchall, C. S. Frampton, G. J. Schrobilgen and J. Valsdóttir, b-Hydroquinone Xenon Clathrate, Acta Cryst., 1989, C45, 944946.

5 J. C. a. Boeyens and J. a. Pretorius, X-ray and neutron diffraction studies of the hydroquinone clathrate of hydrogen chloride, Acta Cryst., 1977, B33, 2120-2124.

6 J.-P. Torré, R. Coupan, M. Chabod, E. Pere, S. Labat, A. Khoukh, R. Brown, J.-M. Sotiropoulos and H. Gornitzka, $\mathrm{CO}_{2}-\mathrm{Hydroquinone}$ Clathrate: Synthesis, Purification, Characterization and Crystal Structure, Cryst. Growth Des., 2016, 16, 5330-5338.

7 E. Eikeland, M. K. Thomsen, J. Overgaard, M. A. Spackman and B. $B$. Iversen, Intermolecular Interaction Energies in Hydroquinone Clathrates at High Pressure, Cryst. Growth Des., 2017, 17, 38343846.

8 M. Ilczyszyn, M. Selent and M. M. Ilczyszyn, Participation of xenon guest in hydrogen bond network of $\beta$-hydroquinone crystal, J. Phys. Chem. A, 2012, 116, 3206-3214.

9 R. F. W. Bader, Atoms in Molecules. A Quantum Theory, Clarendon, Oxford, U.K., 1990.

10 P. Mal, B. Breiner, K. Rissanen and J. R. Nitschke, White phosphorus is air-stable within a self-assembled tetrahedral capsule., Science, 2009, 324, 1697-9.

11 S. H. A. M. Leenders, R. Gramage-Doria, B. de Bruin and J. N. H. Reek, Transition metal catalysis in confined spaces, Chem. Soc. Rev., 2015, 44, 433-448.

12 N. Ahmad, H. A. Younus, A. H. Chughtai and F. Verpoort, Metalorganic molecular cages: applications of biochemical implications, Chem. Soc. Rev., 2015, 44, 9-25.

13 R. Wyler, J. de Mendoza and J. Rebek, A Synthetic Cavity Assembles Through Self-Complementary Hydrogen Bonds, Angew. Chem., Int. Ed. English, 1993, 32, 1699-1701.

14 T. Szabo, G. Hilmersson and J. J. Rebek, Dynamics of Assembly and Guest Exchange in the Tennis Ball, J. Am. Chem. Soc., 1998,
120, 6193-6194.

View Article Online

15 F. Hof, L. C. Palmer and J. J. Rebek, Synthesis anersetfaAssernibly of the Tennis Ball and Subsequent Encapsulation of Methane, J. Chem. Ed., 2001, 78, 1519-1521.

16 D. Tzeli, G. Theodorakopoulos, I. D. Petsalakis, D. Ajami and J. Rebek, Theoretical study of hydrogen bonding in homodimers and heterodimers of amide, boronic acid, and carboxylic acid, free and in encapsulation complexes, J. Am. Chem. Soc., 2011, 133, 16977-16985.

17 D. Tzeli, I. D. Petsalakis, G. Theodorakopoulos, D. Ajami and J. Rebek, Theoretical study of free and encapsulated carboxylic acid and amide dimers, Int. J. Quantum Chem., 2013, 113, 734-739.

18 L. R. MacGillivray and J. L. Atwood, Achiralsphericalmolecular assemblyheldtogetherby 60 hydrogenbonds, Nature, 1997, 389, 469-472.

19 J. L. Atwood, L. J. Barbour and A. Jerga, Organization of the interior of molecular capsules by hydrogen bonding., Proc. Natl. Acad. Sci. U. S. A., 2002, 99, 4837-41.

20 G. M. Whitesides, E. E. Simanek, J. P. Mathias, C. T. Seto, D. N. Chin, M. Mammen and D. M. Gordon, Noncovalent synthesis: using physical-organic chemistry to make aggregates, Acc. Chem. Res., 1995, 28, 37-44.

21 J. M. C. A. Kerckhoffs, M. G. J. Ten Gate, M. A. Mateos-Timoneda, F. W. B. Van Leeuwen, B. Snellink-Ruël, A. L. Spek, H. Kooijman, M. Crego-Calama and D. N. Reinhoudt, Selective selforganization of guest molecules in self-assembled molecular boxes, J. Am. Chem. Soc., 2005, 127, 12697-12708.

22 M. Mascal, I. Yakovlev, E. B. Nikitin and J. C. Fettinger, Fluorideselective host based on anion- $\pi$ interactions, ion pairing, and hydrogen bonding: synthesis and fluoride-ion sandwich complex, Angew. Chem., Int. Ed., 2007, 46, 8782-8784.

23 A. Frontera, F. Saczewski, M. Gdaniec, E. Dziemidowicz-Borys, A. Kurland, P. M. Deyà, D. Quiñonero and C. Garau, Anion- $\pi$ interactions in cyanuric acids: A combined crystallographic and computational study, Chem. - Eur. J., 2005, 11, 6560-6567.

24 S. Kosiorek, B. Rosa, T. Boinski, H. Butkiewicz, M. P. Szymański, O. Danylyuk, A. Szumna and V. Sashuk, Pillar[4]pyridinium: A square-shaped molecular box, Chem. Commun., 2017, 53, 13320-13323.

25 T. D. Della and C. H. Suresh, Anion Encapsulated Fullerenes Behave as Large Anions: A DFT Study, Phys. Chem. Chem. Phys., 2018, 20, 24885-24893.

26 M. B. Hillyer, H. Gan and B. C. Gibb, Precision Switching in a Discrete Supramolecular Assembly: Alkali Metal Ion-Carboxylate Selectivities and the Cationic Hofmeister Effect, ChemPhysChem, 2018, 19, 2285-2289.

27 M. F. Zalazar, E. N. Paredes, G. D. Romero Ojeda, N. D. Cabral and N. M. Peruchena, Study of Confinement and Catalysis Effects of the Reaction of Methylation of Benzene by Methanol in H-Beta and H-ZSM-5 Zeolites by Topological Analysis of Electron Density, J. Phys. Chem. C, 2018, 122, 3350-3362.

28 O. Shameema, C. N. Ramachandran and N. Sathyamurthy, Blue shift in X-H stretching frequency of molecules due to confinement, J. Phys. Chem. A, 2006, 110, 2-4.

29 R. Musat, J. P. Renault, M. Candelaresi, D. J. Palmer, S. Le Caër, R. Righini and S. Pommeret, Finite size effects on hydrogen bonds in confined water, Angew. Chem., Int. Ed., 2008, 47, 8033-8035. 
30 M. J. Frisch, G. W. Trucks, H. B. Schlegel, G. E. Scuseria, M. A Robb, J. R. Cheeseman, J. A. Montgomery, T. Vreven, K. N. Kudin, J. C. Burant, J. M. Millam, S. S. Iyengar, J. Tomasi, V. Barone, B. Mennucci, M. Cossi, G. Scalmani, N. Rega, G. A. Petersson, H. Nakatsuji, M. Hada, M. Ehara, K. Toyota, R. Fukuda, J. Hasegawa, M. Ishida, T. Nakajima, Y. Honda, O. Kitao, H. Nakai, M. Klene, X. Li, J. E. Knox, H. P. Hratchian, J. B. Cross, V. Bakken, C. Adamo, J. Jaramillo, R. Gomperts, R. E. Stratmann, O. Yazyev, A. J. Austin, R. Cammi, C. Pomelli, J. W. Ochterski, P. Y. Ayala, K. Morokuma, G. A. Voth, P. Salvador, J. J. Dannenberg, V. G. Zakrzewski, S. Dapprich, A. D. Daniels, M. C. Strain, O. Farkas, D. K. Malick, A. D. Rabuck, K. Raghavachari, J. B. Foresman, J. V. Ortiz, Q. Cui, A. G. Baboul, S. Clifford, J. Cioslowski, B. B. Stefanov, G. Liu, A. Liashenko, P. Piskorz, I. Komaromi, R. L. Martin, D. J. Fox, T. Keith, A. Laham, C. Y. Peng, A. Nanayakkara, M. Challacombe, P. M. W. Gill, B. Johnson, W. Chen, M. W. Wong, C. Gonzalez and J. A Pople, Gaussian 03, Revision C.02, Gaussian, Inc., Wallingford CT, 2004.

31 J.-D. Chai and M. Head-Gordon, Long-range corrected hybrid density functionals with damped atom-atom dispersion corrections, Phys. Chem. Chem. Phys., 2008, 10, 6615-6620.

32 Z. Li, G. Chen, Y. Xu, X. Wang and Z. Wang, Study of the Structural and the Spectral Characteristics of $\left[\mathrm{C}_{3} \mathrm{~N}_{3}\left(\mathrm{NH}_{2}\right)_{3}\right]_{n}(\mathrm{n}=1-4)$ Clusters, J. Phys. Chem. A, 2013, 117, 12511-12518.

33 A. N. Petelski, D. J. R. Duarte, S. C. Pamies, N. M. Peruchena and G. L. Sosa, Intermolecular perturbation in the self-assembly of melamine, Theor. Chem. Acc., 2016, 135, 65.

34 A. N. Petelski, N. M. Peruchena, S. C. Pamies and G. L. Sosa, Insights into the self-assembly steps of cyanuric acid toward rosette motifs: a DFT study, J. Mol. Model., 2017, 23, 263.

35 C. Fonseca Guerra, H. Zijlstra, G. Paragi and F. M. Bickelhaupt, Telomere Structure and Stability: Covalency in Hydrogen Bonds, Not Resonance Assistance, Causes Cooperativity in Guanine Quartets, Chem. - Eur. J., 2011, 17, 12612-12622.

36 S. F. Boys and F. Bernardi, The calculation of small molecular interactions by the differences of separate total energies. Some procedures with reduced errors, Mol. Phys., 1970, 19, 553-559.

37 T. A. Keith, AIMAll (Version 11.12.19), TK Gristmill Software, Overland Park KS, USA, 2011, aim.tkgristmill.com.

38 T. Lu, F. Chen, Multiwfn: A multifunctional wavefunction analyzer, J. Comput. Chem., 2012, 33, 580-592.

39 R. F. W. Bader, M. T. Caroll, J. R. Cheeseman and C. Chang, Properties of atoms in molecules: atomic volumes, J. Am. Chem. Soc., 1987, 109, 7968-7979.

$40 \mathrm{P}$. Su and H. Li, Energy decomposition analysis of covalent bonds and intermolecular interactions, J. Chem. Phys., 2009, 131 014102

41 M. W. Schmidt, K. K. Baldridge, J. A. Boatz, S. T. Elbert, M. S. Gordon, J. H. Jensen, S. Koseki, N. Matsunaga, K. A. Nguyen, S. $\mathrm{Su}$, T. L. Windus, M. Dupuis and J. A. Montgomery, General Atomic and Molecular Electronic Structure System, J. Comput. Chem., 1993, 14, 1347-1363.

42 CYLview, 1.0b; C. Y. Legault, Université de Sherbrooke, 2009 (http://www.cylview.org).

43 W. Humphrey, A. Dalke and K. Schulten, VMD - Visual Molecular Dynamics, J. Mol. Graph., 1996, 14, 33-38.

44 T. Steiner, The Hydrogen Bond in the Solid State, Angew. Chem.
Int. Ed., 2002, 41, 48-76.

View Article Online

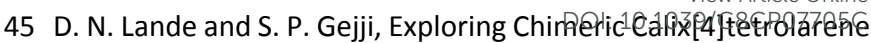
Molecular Scaffolds: Theoretical Investigations, J. Phys. Chem. A, 2018, 122, 4189-4197.

46 P. Murphy, S. J. Dalgarno and M. J. Paterson, Transition Metal Complexes of Calix[4]arene: Theoretical Investigations into Small Guest Binding within the Host Cavity, J. Phys. Chem. A, 2016, 120, 824-839.

47 A. N. Petelski, N. M. Peruchena and G. L. Sosa, Evolution of the hydrogen-bonding motif in the melamine-cyanuric acid cocrystal: a topological study, J. Mol. Model., 2016, 22, 202.

48 N. J. M. Amezaga, S. C. Pamies, N. M. Peruchena and G. L. Sosa, Halogen bonding: a study based on the electronic charge density., J. Phys. Chem. A, 2010, 114, 552-562.

49 C. F. Matta, J. Hernández-Trujillo, T. H. Tang and R. F. W. Bader, Hydrogen - Hydrogen bonding: A stabilizing interaction in molecules and crystals, Chem. - Eur. J., 2003, 9, 1940-1951.

50 F. H. Allen, C. M. Bird, R. S. Rowland and P. R. Raithby, ResonanceInduced Hydrogen Bonding at Sulfur Aeceptors in R1R2C $=\mathrm{S}$ and R1CS2 Systems, Acta Cryst., 1997, B53, 680-695.

51 F. Zaccaria, G. Paragi and C. Fonseca Guerra, The Role of Alkali Metal Cations in the Stabilization of Guanine Quadruplexes: Why $\mathrm{K}^{+}$is the best., Phys. Chem. Chem. Phys., 2016, 18, 20895-20904.

52 A. O. Ortolan, I. Østrøm, G. F. Caramori, R. L. T. Parreira, E. H. Da Silva and F. M. Bickelhaupt, Tuning Heterocalixarenes to Improve Their Anion Recognition: A Computational Approach, J. Phys. Chem. A, 2018, 122, 3328-3336.

53 O. B. Berryman, V. S. Bryantsev, D. P. Stay, D. W. Johnson and B. P. Hay, Structural criteria for the design of anion receptors: The interaction of halides with electron-deficient arenes, J. Am. Chem. Soc., 2007, 129, 48-58.

54 F. Hettche, P. Rei $\beta$ and R. W. Hoffmann, Effect of conformational preorganization of a three-armed host on anion binding and selectivity, Chem. - Eur. J., 2002, 8, 4946-4956.

55 C. T. Seto and G. M. Whitesides, Molecular self-assembly through hydrogen bonding: supramolecular aggregates based on the cyanuric acid-melamine lattice, J. Am. Chem. Soc., 1993, 115, 905-916.

56 A. O. Ortolan, G. F. Caramori, F. Matthias Bickelhaupt, R. L. T. Parreira, A. Muñoz-Castro and T. Kar, How the electron-deficient cavity of heterocalixarenes recognizes anions: Insights from computation, Phys. Chem. Chem. Phys., 2017, 19, 24696-24705.

57 R. F. W. Bader, A Bond Path: A Universal Indicator of Bonded Interactions, J. Phys. Chem. A, 1998, 102, 7314-7323.

58 F. Guo, E. Y. Cheung, K. D. M. Harris and V. R. Pedireddi, Contrasting Solid-State Structures of Trithiocyanuric Acid and Cyanuric Acid, Cryst. Growth Des., 2006, 6, 846-848.

59 E. L. Angelina, D. J. R. Duarte and N. M. Peruchena, Is the decrease of the total electron energy density a covalence indicator in hydrogen and halogen bonds?, J. Mol. Model., 2013, 19, 2097-106.

60 D. J. R. Duarte, G. L. Sosa and N. M. Peruchena, Nature of halogen bonding. A study based on the topological analysis of the Laplacian of the electron charge density and an energy decomposition analysis., J. Mol. Model., 2013, 19, 2035-41.

61 J.-W. Zou, M. Huang, G.-X. Hu and Y.-J. Jiang, Toward a uniform description of hydrogen bonds and halogen bonds: correlations 
of interaction energies with various geometric, electronic and topological parameters, RSC Adv., 2017, 7, 10295-10305.

62 C. F. Guerra, J. Handgraaf, E. J. Baerends and F. M. Bickelhaupt, Voronoi Deformation Density (VDD) Charges: Assessment of the Mulliken, Bader, Hirshfeld, Weinhold, and VDD, J. Comput. Chem., 2003, 25, 189-210.

63 F. Cortés-Guzmán and R. F. W. Bader, Complementarity of QTAIM and MO theory in the study of bonding in donor acceptor complexes, Coord. Chem. Rev., 2005, 249, 633-662.

64 K. T. Mahmudov, M. N. Kopylovich, A. M. Maharramov, M. M. Kurbanova, A. V. Gurbanov and A. J. L. Pombeiro, Barbituric acids as a useful tool for the construction of coordination and supramolecular compounds, Coord. Chem. Rev., 2014, 265, 1-37.

65 J. Martin-Gil, F. J. Martin-Gil, M. Perez-Mendez and J. Fayos, Structure of $\mathrm{K}_{2}\left(\mathrm{Pt}_{2} \mathrm{I}_{6}\right) \cdot 2 \mathrm{C}_{4} \mathrm{H}_{4} \mathrm{~N}_{2} \mathrm{O}_{3}$, Z. Kristallogr., 1985, 173, 179.

66 V. T. Yilmaz, F. Yilmaz, H. Karakaya, O. Büyükgüngör and W. T. A. Harrison, Silver(I)-barbital based frameworks: Syntheses, crystal structures, spectroscopic, thermal and antimicrobial activity studies, Polyhedron, 2006, 25, 2829-2840. 
Table of contents entry:

\section{Impact of Confinement in Multimolecular Inclusion Compounds of Melamine and Cyanuric Acid}

Andre Nicolai Petelski, ${ }^{a}$ Silvana Carina Pamies, ${ }^{a}$ Agustín Gabriel Sejas, ${ }^{a}$ Nélida María Peruchena, ${ }^{* b, c}$ and Gladis Laura Sosa*a,c

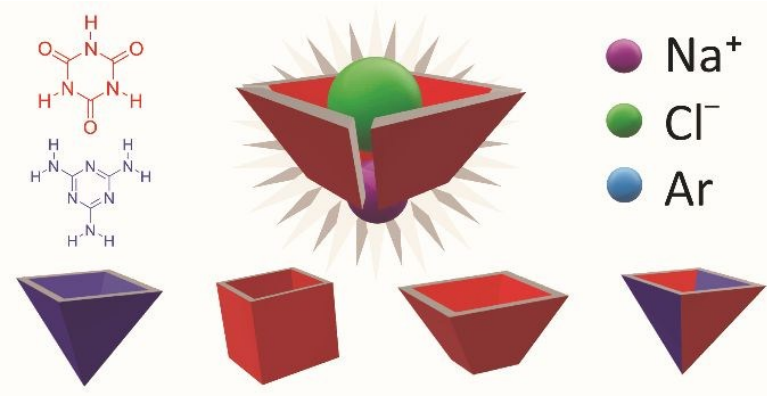

Cyanuric acid is shown to be the best supramolecular building block to obtain cage-like clusters. Its triazine ring is also superior to the melamine one to capture anions as well as cations. 